\title{
Estimating the radiation absorbed by a human
}

\author{
Natasha A. Kenny • Jon S. Warland • \\ Robert D. Brown - Terry G. Gillespie
}

Received: 23 October 2007 / Revised: 19 December 2007 / Accepted: 6 January 2008 / Published online: 14 February 2008 (C) ISB 2008

\begin{abstract}
The complexities of the interactions between long- and short-wave radiation fluxes and the human body make it inherently difficult to estimate precisely the total radiation absorbed $(R)$ by a human in an outdoor environment. The purpose of this project was to assess and compare three methods to estimate the radiation absorbed by a human in an outdoor environment, and to compare the impact of applying various skin and clothing albedos $\left(\alpha_{h}\right)$ on $R$. Field tests were conducted under both clear and overcast skies to evaluate the performance of applying a cylindrical radiation thermometer (CRT), net radiometer, and a theoretical estimation model to predict $R$. Three albedos were evaluated: light $\left(\alpha_{h}=0.57\right)$, medium $\left(\alpha_{h}=0.37\right)$, and dark $\left(\alpha_{h}=\right.$ 0.21 ). During the sampling periods, the range of error between the methods used to estimate the radiation absorbed by a cylindrical body under clear and overcast skies ranged from 3 to $8 \%$. Clothing and skin albedo had a substantial impact on $R$, with the mean change in $R$ between the darkest and lightest albedos ranging from 115 to $157 \mathrm{~W} \mathrm{~m}^{-2}$ over the sampling period. Radiation is one of the most important variables to consider in outdoor thermal comfort research, as $R$ is often the largest contributor to the human energy balance equation. The methods outlined and assessed in this study can be conveniently applied to provide
\end{abstract}

N. A. Kenny $(\bowtie) \cdot$ J. S. Warland · T. G. Gillespie

Department of Land Resource Science,

University of Guelph, Guelph, Ontario, Canada

e-mail: nkenny@uoguelph.ca

R. D. Brown

School of Environmental Design and Rural Development,

University of Guelph, Guelph, Ontario, Canada reliable estimates of the radiation absorbed by a human in an outdoor environment.

Keywords Radiation (absorbed) • Human • Outdoor environment • Thermal comfort • Clothing and skin albedo

\section{List of symbols and abbreviations}

$A_{c s} \quad$ cross sectional area of the cylinder $\left(\mathrm{m}^{2}\right)$

$A_{c y l} \quad$ outer surface area of the cylinder $\left(\mathrm{m}^{2}\right)$

$A_{\text {eff }} \quad$ effective area factor

$D \quad$ Diameter of a cylinder (m)

$k \quad$ thermal diffusivity of air $\left(\sim 22 \times 10^{-6} \mathrm{~m}^{2} \mathrm{~s}^{-1}\right)$

$K_{b} \quad$ incoming direct beam radiation incident on a horizontal surface $\left(\mathrm{W} \mathrm{m}^{-2}\right)$

$K_{d} \quad$ incoming diffuse radiation $\left(\mathrm{W} \mathrm{m}^{-2}\right)$

$K_{o} \quad$ solar constant $\left(\sim 1367 \mathrm{~W} \mathrm{~m}^{-2}\right)$

$K_{p} \quad$ incoming direct beam radiation received on a surface perpendicular to the beam $\left(\mathrm{W} \mathrm{m}^{-2}\right)$

$K_{r} \quad$ reflected solar radiation $\left(\mathrm{W} \mathrm{m}^{-2}\right)$

$K_{t} \quad$ total incoming solar radiation $\left(\mathrm{W} \mathrm{m}^{-2}\right)$

$K_{b(a b s)}$ direct beam solar radiation absorbed by a vertical cylinder $(\mathrm{W})$

$K_{d(a b s)} \quad$ diffuse solar radiation absorbed by a vertical cylinder $(\mathrm{W})$

$L_{a} \quad$ atmospheric long-wave radiation $\left(\mathrm{W} \mathrm{m}^{-2}\right)$

$L_{g} \quad$ long-wave radiation emitted from the ground surface $\left(\mathrm{W} \mathrm{m}^{-2}\right)$

$L_{a(a b s)} \quad$ atmospheric long-wave radiation absorbed by a cylinder (W)

$L_{g(a b s)} \quad$ ground surface long-wave radiation absorbed by a cylinder $(\mathrm{W})$

$m \quad$ optical mass number 


\begin{tabular}{|c|c|}
\hline$P$ & clothing permeability $\left(\mathrm{ft}^{3} \mathrm{ft}^{-2} \min ^{-1}\right)$ \\
\hline $\operatorname{Pr}$ & Prandtl number \\
\hline$P_{a}$ & atmospheric pressure $(\mathrm{kPa})$ \\
\hline$R$ & radiation absorbed $\left(\mathrm{W} \mathrm{m}^{-2}\right)$ \\
\hline $\operatorname{Re}$ & Reynolds number \\
\hline RH & relative humidity (\%) \\
\hline$R_{E}$ & $\begin{array}{l}\text { radiation absorbed calculated using theoreti- } \\
\text { cal estimates of radiation fluxes }\end{array}$ \\
\hline$r_{m}$ & resistance of the cylinder $\left(\mathrm{s} \mathrm{m}^{-1}\right)$ \\
\hline$r_{c o}$ & clothing resistance $\left(\mathrm{s} \mathrm{m}^{-1}\right)$ \\
\hline$R_{N R}$ & $\begin{array}{l}\text { radiation absorbed calculated using net } \\
\text { radiometer measurements }\left(\mathrm{W} \mathrm{m}^{-2}\right)\end{array}$ \\
\hline$R_{R T}$ & $\begin{array}{l}\text { radiation absorbed calculated using a cylindri- } \\
\text { cal radiation thermometer }\left(\mathrm{W} \mathrm{m}^{-2}\right)\end{array}$ \\
\hline$T_{a}$ & air temperature $\left({ }^{\circ} \mathrm{C}\right)$ \\
\hline$T_{m r t}$ & mean radiant temperature $\left({ }^{\circ} \mathrm{C}\right)$ \\
\hline$T_{r t}$ & $\begin{array}{l}\text { equilibrium temperature of the cylindrical } \\
\text { radiation thermometer }\end{array}$ \\
\hline$V$ & air velocity $\left(\mathrm{m} \mathrm{s}^{-1}\right)$ \\
\hline$v$ & kinematic viscosity of air $\left(\sim 1.5 \times 10^{-5} \mathrm{~m}^{2} \mathrm{~s}^{-1}\right)$ \\
\hline$z$ & height $(\mathrm{m})$ \\
\hline$\alpha_{h}$ & average skin and clothing albedo of a human \\
\hline$\alpha_{g r}$ & albedo of the ground surface \\
\hline$\psi$ & zenith angle $\left(^{\circ}\right)$ \\
\hline$\rho C_{p}$ & $\begin{array}{l}\text { volumetric heat capacity of air } \\
\left(\sim 1200 \mathrm{~J} \mathrm{~m}^{-3} \mathrm{~K}^{-4}\right)\end{array}$ \\
\hline$\tau$ & atmospheric transmittance \\
\hline$\sigma$ & 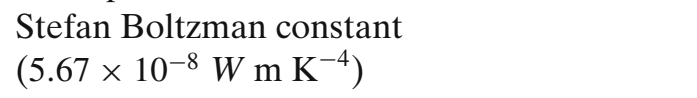 \\
\hline$\varepsilon$ & emissivity \\
\hline$\varepsilon_{h}$ & emissivity of a human \\
\hline CRT & cylindrical radiation thermometer \\
\hline MAD & mean absolute deviation \\
\hline MBE & mean bias error \\
\hline RMSE & root mean square error \\
\hline
\end{tabular}

\section{Introduction}

In any environment, there is a continuous exchange of radiant energy that is reflected, absorbed and/or transmitted. Thermal comfort is influenced by short-wave (solar) radiation and long-wave (terrestrial) radiation. Solar radiation $(\sim 0.3-4 \mu \mathrm{m})$ is received in the form of visible light and solar infrared radiation. Terrestrial radiation $(\sim 4-100 \mu \mathrm{m})$ is emitted as a function of an object's temperature and emissivity.

Thermal comfort is specifically affected by the radiant energy that is absorbed and the radiation that is emitted or reflected back into the environment by the human body. The radiant flux density incident and emitted by a surface is commonly expressed in units of
$\mathrm{W} \mathrm{m} \mathrm{m}^{-2}$. The radiation flux inputs are one of the most important components in the human energy balance, as the heat load received by a human in full sun is certain to be larger than resting metabolic rates (Matzarakis et al. 2007; Nielsen 1990).

Effective methods of measurement and prediction of this input are required for accurate analysis of thermal comfort in outdoor environments (Blazejczyk et al. 1993). Radiation fluxes vary considerably over space and time, reflecting both the dynamic state of the meteorological variables and radiative properties of surfaces that govern the radiation absorbed by objects in the ground hemisphere (Jendritzky and Nubler 1981). The complexities of the interactions between the solar and terrestrial radiation fluxes in the sky and ground hemispheres and the human body make it inherently difficult to estimate precisely the total radiation absorbed $(R)$ by a human in an outdoor environment.

Traditional approaches to estimating $R$ in outdoor thermal comfort research can be time-consuming, expensive, cumbersome, and may not adequately address the contribution of the short- and long-wave radiation fluxes on the human body (Hodder and Parsons 2007; La Gennusa et al. 2005). Although $R$ can be modeled based on planar measurements of incoming and outgoing short- and long-wave radiation fluxes, readily available radiation data can often be difficult to obtain, as the incoming and outgoing solar and terrestrial radiation fluxes are not all commonly observed variables at many meteorological stations, and the equipment used to make these measurements is costly and highly specialized (Baigorria et al. 2004; Gul et al. 1998). Reliable estimates of the incoming and outgoing solar and terrestrial fluxes received on a horizontal plane can often be obtained using the basic principles of environmental biophysics (e.g., Campbell and Norman 1998; Monteith and Unsworth 1990).

Both measured and estimated planar radiation values must be subsequently modeled to provide an accurate estimate of the radiation incident on a human body, which is often represented as a vertical cylinder. Methods for converting the planar measurements to three-dimensional form can be complex, requiring short- and long-wave recordings in multiple directions, thus making $R$ difficult to both measure and compute using planar radiation measurements (Matzarakis et al. 2007; Parsons 2003). However, based on the geometry of long- and short-wave radiation fluxes (e.g., Oke 1987), it is possible to model the radiation absorbed by a vertical cylinder based on one horizontal measure of the incoming and outgoing short- and long-wave radiation fluxes. 
Methods have been developed to apply relatively simple on-site sensors to model the radiation absorbed by a human. In thermal comfort research, radiation is commonly modeled through application of the mean radiant temperature $\left(T_{m r t}\right)\left({ }^{\circ} \mathrm{C}\right)$. Originally developed for application in indoor environments, $T_{m r t}$ is described as the uniform temperature of a hypothetical enclosure that would result in the same radiant heat transfer with the subject as in the actual complex environment (Fanger 1972; Matzarakis et al. 2007). $T_{m r t}$ is frequently modeled using a globe thermometer (Nikolopoulou and Lykoudis 2006; Thorsson et al. 2004; Nikolopoulou et al. 2001; Schiller 2001). Based upon the equilibrium temperature of the globe and an energy balance approach to modeling the radiative and convective heat fluxes from the sensor, $T_{m r t}$ is calculated based upon the globe temperature, air temperature and air velocity (Thorsson et al. 2007; Fanger 1972). Although the shape of the globe thermometer is appropriate for the isotropic fluxes of long-wave radiation, in an outdoor environment where a significant portion of the radiation received is parallel direct beam short-wave radiation, the globe shape and color may impact the instrument's ability to accurately represent the human body (Thorsson et al. 2007; Krys and Brown 1990; Brown and Gillespie 1995).

Recent studies have applied an approach to modeling $T_{m r t}$ based upon an integration of the short- and long-wave radiation flux measurements and angular factors in relation to the human body in complex outdoor settings (Ali-Toudert et al. 2005; Ali-Toudert and Mayer 2006; Thorsson et al. 2007). Through this integrated approach, $T_{m r t}$ is modeled based upon the sum of all short- and long-wave radiation fluxes impacting the human body in multiple directions. Although this approach has been adapted to more accurately represent the impact of radiation on the human body, the required measurements and calculations can be both costly and complex (Thorsson et al. 2007).

An inexpensive and convenient means of estimating the net radiation flux density on a human in an outdoor environment can be obtained through the use of a cylindrical radiation thermometer (CRT) (Krys and Brown 1990; Brown and Gillespie 1986). A CRT consists of an aluminum or copper cylinder, approximately $10 \mathrm{~mm}$ in diameter and $100 \mathrm{~mm}$ in length, that is painted to have an albedo and emissivity similar to the average human skin and clothing. It is designed to produce an $R$ value that is an integration of the total solar and terrestrial radiation fluxes that are absorbed by a cylindrical body. The CRT contains an internal temperature sensor, such as a thermistor or thermocouple, for electronic monitoring. The radiation absorbed by the cylinder is modeled based on the energy budget approach, where the long- and short-wave radiation absorbed is equal to the long-wave radiation emitted plus the convective heat losses. Once the CRT has attained a steady temperature, simultaneous measurements of air temperature and wind speed, and application of Ohm's law analogy for convection, can be applied to determine the energy budget of the cylinder $\left(\mathrm{W} \mathrm{m}^{-2}\right)$. Although research has suggested that the CRT provides an efficient and accurate method of estimating $R$ in an outdoor environment (Krys and Brown 1990), this method has been criticized for providing an over-simplification of the dynamic effect of radiation on the human form (Blazejczyk et al. 1993).

The goal of this paper is to assess and compare three methods to estimate the total radiation absorbed $(R)$ by a human using:

- a theoretical estimation model based on the basic principles of environmental biophysics that requires no on-site radiation measurements;

- horizontal measurements provided by a planar net radiometer;

- a simple-to-construct cylindrical radiation thermometer (CRT).

These goals will be accomplished through the following objectives:

- to summarize the theoretical equations used in the above noted methods for estimating $R$;

- to provide an overview of the experimental techniques applied to estimate $R$ under both clear and overcast skies;

- to evaluate the impact of applying various clothing and skin albedos when estimating $R$;

- to provide a comprehensive overview of the results and a discussion of their relevance to current human biometeorological research, and their potential application in outdoor thermal comfort research.

As the radiation absorbed by a human in an outdoor environment is a cross-disciplinary topic, this paper has been written to reach a broad audience including academics, architects, engineers, landscape architects and planners. Therefore, a comprehensive review of many of the basic principles and equations of environmental biophysics are presented. 


\section{Theory}

Estimation of horizontal fluxes under clear sky conditions using the basic principles of meteorological biophysics

The following section outlines a theoretical model to estimate the radiation received on a horizontal plane with the following inputs: the solar constant, atmospheric transmissivity, location (latitude and elevation), atmospheric pressure, surface albedo and air temperature. The following equations for estimating the incoming and outgoing short- and long-wave radiation fluxes are intended for application under clear sky conditions and a full sky view.

\section{Solar radiation}

Solar radiation absorbed by a human in an outdoor environment is a substantial contributor to the body's energy budget (Blazejczyk et al. 1998). The total solar radiation load on a human is composed of: the incoming direct beam radiation $\left(K_{b}\right)$, the diffuse radiation $\left(K_{d}\right)$ that is scattered as the direct beam passes through the earth's atmosphere, and the radiation that is reflected from the ground hemisphere $\left(K_{r}\right)$.

Separating solar radiation into the direct and diffuse components is necessary as the intensity and geometric characteristics of each vary greatly. Incoming direct radiation is received in a parallel beam, while diffuse radiation is isotropic and scattered from all directions in the sky and ground hemispheres (Monteith and Unsworth 1990). Although the ratio of incoming direct to diffuse radiation depends upon the elevation of the sun and degree of cloud cover in the atmosphere, under clear sky conditions, direct beam radiation can comprise in excess of $90 \%$ of the total radiation received in the visible and near-infrared bands (Driscoll 1985). As these are the wavelengths most responsible for heating, the direct beam component can be an important contributor to radiative heating and the overall energy budget of humans.

The incoming direct beam solar radiation $\left(\mathrm{W} \mathrm{m}^{-2}\right)$ incident on a horizontal surface can be estimated as (Campbell and Norman 1998):

$K_{b}=K_{p} \cos \psi$

where $\psi$ is the solar zenith angle $\left(^{o}\right)$ and $K_{p}$ is the incoming direct irradiance that is received on a surface perpendicular to the beam. The term $K_{p}$ can be estimated as (Campbell and Norman 1998):

$K_{p}=K_{o} \tau^{m}$ where $K_{o}$ is the solar constant defined as the radiant energy emitted by the sun as observed at the top of the earth's atmosphere on a plane surface placed normal to the solar beam $\left(\sim 1,367 \mathrm{~W} \mathrm{~m}^{-2}\right)$ (Brock and Richardson 2001; Oke 1987), and $\tau$ is the atmospheric transmittance. Atmospheric transmittance will vary both spatially and temporally, but generally varies between 0.6 to 0.75 for clear sky conditions (Campbell and Norman 1998; Terjung and Louie 1971). The term $m$ is the optical air mass number. For zenith angles less than $80^{\circ}$, it can be estimated as (Campbell and Norman 1998):

$m=\frac{P_{a}}{101.3 \cos \psi}$

where $P_{a}$ is the atmospheric pressure $(\mathrm{kPa})$ at the observation site (the value $101.3 \mathrm{kPa}$ is the sea level atmospheric pressure).

On clear days, the diffuse incoming radiation can be calculated as (Campbell and Norman 1998):

$K_{d}=0.3\left(1-\tau^{m}\right) K_{o} \cos \psi$

The amount of total incoming solar radiation that is reflected from the ground hemisphere is estimated as:

$K_{r}=\alpha_{g r} K_{t}$

where $\alpha_{g r}$ is the albedo of the ground surface and $K_{t}$ is the total incoming solar radiation as represented by:

$K_{t}=K_{b}+K_{d}$

\section{Terrestrial radiation}

Monteith and Unsworth (1990) suggest two simple equations that were developed based on a linear approximation of the dependence of full radiation on temperatures above $283 \mathrm{~K}$. The equations for estimating the incoming long-wave radiation emitted from the sky hemisphere $\left(L_{a}\right)$ and the outgoing long-wave radiation emitted by the ground hemisphere $\left(L_{g}\right)$ under clear sky conditions are:

$L_{a}=213+5.5 T_{a}$

and,

$L_{g}=320+5.2 T_{a}$

where $T_{a}$ is the air temperature $\left({ }^{\circ} C\right)$.

The intention of the present study was to apply a basic method for estimating the radiation fluxes in an 
outdoor environment. For complex outdoor environments, a more sophisticated approach to modeling $L_{a}$ as a function of vapour pressure and air temperature and $L_{g}$ as a function of the measured surface temperature may be preferred (e.g., Oke 1987; Ali-Toudert et al. 2005).

Measuring radiation fluxes using a horizontal net radiometer

Radiometers are the most common and reliable means of collecting radiation data: pyranometers are used to measure both direct solar beam and diffuse sky radiation, pyrgeometers are used to measure terrestrial radiation, and net radiometers are designed to measure the difference between incoming and outgoing radiative energy fluxes (Brock and Richardson 2001). On-site measurements for the incoming and outgoing radiation fluxes can be obtained with a net radiometer that is designed with two (one upwards facing and one downward facing) pyranometers and pyrgeometers, and thus is capable of measuring all four radiation components separately (e.g., Model CNR1; Kipp \& Konen, Delft, Netherlands). Pyranometers are designed to provide $K_{t}$ and thus do not provide separate measurements for the incoming sky diffuse and direct beam solar radiation. By combining equations 1,2 , and $4, K_{b}$ can be estimated under clear sky conditions as a proportion of $K_{t}$ as:

$K_{b}=\frac{K_{t}}{1+\frac{0.3\left(1-\tau^{m}\right)}{\tau^{m}}}$

and $K_{d}$ becomes:

$K_{d}=K_{t}-K_{b}$

Modeling the radiation absorbed by a human from horizontal radiation fluxes

Data calculated using the estimation model or measurements obtained from radiometers are based on the radiation received by a horizontal surface and require mathematical interpretation to represent the radiation absorbed by a human. A vertical cylinder is commonly used to represent the human body in a standing position (Krys and Brown 1990; Monteith and Unsworth 1990; Campbell 1977), where the total radiation that is absorbed is equal to the absorbed diffuse and direct beam solar radiation plus the solar radiation that is reflected from the ground hemisphere, in addition to the absorbed atmospheric long-wave radiation plus the longwave radiation received from the ground hemisphere.

\section{The radiation absorbed by a vertical cylinder}

The following equations are used to convert the data generated by the theoretical estimation model (Eqs. 1-8) and the planar measurements obtained using on-site radiometer measurements to the radiation absorbed by a vertical cylinder.

The total incoming direct beam radiation absorbed by the vertical cylinder (W) is calculated based upon the direct irradiance received perpendicular to the beam as:

$K_{b(a b s)}=\left(1-\alpha_{h}\right) K_{p} \sin \psi A_{c s}$

where $\mathrm{A}_{c s}$ is the cross-sectional area of the cylinder, and $\alpha_{h}$ is the albedo which is used to represent the average skin and clothing albedo of a human in an outdoor environment. Skin albedo generally varies from 0.4 to 0.45 for light skin tones and from 0.2 to 0.25 for darker skin tones (Monteith and Unsworth 1990; Driscoll 1985). Although the albedo of clothing can vary greatly depending upon both clothing color and texture, Brown and Gillespie (1986) recommend an average skin and clothing albedo of 0.37 for application in outdoor thermal comfort research, Terjung and Louie (1971) applied an average albedo of 0.40 and Blazejczyk et al. (1993) applied an average albedo of 0.33 to model the solar radiation absorbed by a human in an outdoor environment.

To model the radiation absorbed using on-site radiometer measurements $\left(R_{N R}\right)$, equations (9) and (10) are applied to separate the total incoming short-wave diffuse and direct beam fluxes and then equation (1) is applied to convert the incoming direct beam solar radiation incident on a horizontal surface, to that received on a surface perpendicular to the beam.

It is assumed that $K_{d}, K_{r}, L_{a}$, and $L_{g}$ are received as isotropic fluxes. Therefore, the total radiation absorbed (W) becomes:

$$
\begin{aligned}
K_{d(a b s)} & =0.5\left(1-\alpha_{h}\right) K_{d} A_{c y l} \\
L_{a(a b s)} & =0.5 \varepsilon_{h} L_{a} A_{c y l} \\
L_{g(a b s)} & =0.5 \varepsilon_{h} L_{g} A_{c y l}
\end{aligned}
$$

where $A_{c y l}$ is the outer surface area of the cylinder, $\varepsilon_{h}$ is the emissivity of a human $(\sim 0.95)$ and the view factor of the cylinder is 0.5 , since any point on the cylinder 'sees' half of the sky hemisphere and half of the ground hemisphere.

Under overcast skies, there is no beam components $\left(K_{b}=0 \mathrm{~W} \mathrm{~m}^{-2}\right)$ and $K_{t}$ is entirely diffuse. Therefore, the total incoming solar radiation absorbed (W) is calculated based on equation (12). 
The total radiation absorbed by a human $\left(\mathrm{W} \mathrm{m}^{-2}\right)$ then can be calculated based on the theoretical estimates or measurements obtained by radiometers as:

$R=\frac{K_{b(a b s)}+K_{d(a b s)}+L_{a(a b s)}+L_{g(a b s)}}{A_{c y l}}$

Calculating radiation absorbed using a cylindrical radiation thermometer

The radiation absorbed by a CRT is modeled based on the steady state energy budget of the cylinder, where the radiation absorbed $\left(\mathrm{W} \mathrm{m}^{-2}\right)$ is equal to the radiation emitted by the cylinder (calculated based on the Stefan-Boltzman equation) plus the convective heat transfer between the cylinder and the ambient environment. The radiation absorbed by the cylinder is calculated as:

$R_{R T}=\varepsilon \sigma\left(T_{r t}+273.15\right)^{4}+\rho C_{p} \frac{\left(T_{r t}-T_{a}\right)}{r_{m}}$

where $\varepsilon$ is the emissivity of the cylinder $(\sim 0.95) \sigma$ is the Stefan-Boltzman constant $\left(5.67 \times 10^{-8} \mathrm{~W} \mathrm{~m}^{-2} \mathrm{~K}^{-4}\right), \rho C_{p}$ is the volumetric heat capacity of air $\left(\sim 1,200 \mathrm{~J} \mathrm{~m}^{-3} \mathrm{~K}^{-4}\right)$, and $\mathrm{T}_{r t}$ is the equilibrium temperature of the CRT $\left({ }^{\circ} \mathrm{C}\right)$ (Brown and Gillespie 1986). The resistance of the cylinder to sensible heat transfer $\left(\mathrm{r}_{m}\right)\left(\mathrm{s} \mathrm{m}^{-1}\right)$ is determined from engineering heat transfer theory from the expression:

$r_{m}=\frac{D}{A \operatorname{Re}^{n} \operatorname{Pr}^{0.33} \mathrm{k}}$

where $R e$ is Reynolds number $\left(V D v^{-1}\right), P r$ is Prandtl number (0.71), $D$ is the diameter of the cylinder, $V$ is the free stream air velocity, $v$ is the kinematic viscosity of air $\left(\sim 1.5 \times 10^{-5} \mathrm{~m}^{2} \mathrm{~s}^{-1}\right), k$ is the thermal diffusivity of the air $\left(\sim 22 \times 10^{-6} \mathrm{~m}^{2} \mathrm{~s}^{-1}\right)$ and $A$ and $n$ are empirical constants derived from experiments on heat flow from cylinders: when $\operatorname{Re}<4,000, A=0.683$ and $n=0.466$; if $R e>4,000<40,000, A=0.193$ and $n=0.618$; and if $R e>40,000 A=0.0266$ and $n=0.805$ (Kreith and Black 1980).

\section{Methods}

The following section outlines the methods applied to compare three methods for estimating the radiation absorbed by a human based on the following definitions:

- $R_{E}$ is the radiation absorbed by a cylindrical body calculated based upon theoretical estimates of the incoming and outgoing radiation fluxes and requiring no on-site radiation measurements;
- $R_{N R}$ is the radiation absorbed by a cylindrical body calculated based upon the on-site horizontal longand short-wave radiation measurements provided by a net radiometer;

- $R_{R T}$ is the radiation absorbed by a cylindrical body calculated based upon the on-site measurements of a cylindrical radiation thermometer.

Field tests

Field tests were conducted at the Elora Meteorological Research Station ( $43^{\circ} 38^{\prime} \mathrm{N}, 80^{\circ} 24^{\prime} \mathrm{W}$, elevation $346 \mathrm{~m}$, $\left.\alpha_{g r}=0.20\right)$ on the following dates:

- $\quad$ To evaluate the performance of the $R_{N R}, R_{R T}$ and $R_{E}$ methods under clear sky conditions, tests were conducted from 0800 hours to 1800 hours on June 11th-14th, 2007;

- To evaluate the performance of the $R_{N R}$ and $R_{R T}$ methods under overcast conditions, a test was conducted from 1000 hours to 1300 hours on 22 August 2007;

- To evaluate the effect of applying various clothing and skin albedos on $R$ under clear sky conditions, a test was conducted from 1100 hours to 1600 hours on 31 August 2007.

The CRT as described by Brown and Gillespie (1986) and Krys and Brown (1990) was modified for electronic monitoring using a copper-constantan thermocouple (Fig. 1). The thermocouple junction was inserted to the midpoint of a piece of copper pipe $110 \mathrm{~mm}$ in length and $9.50 \mathrm{~mm}$ in diameter, which was filled with a conductive epoxy (OMEGABOND 101; Omega Engineering, Quebec). To represent the radiative properties of a human, the CRT was painted to have an albedo of 0.37 and an emissivity of 0.95 . To evaluate the effect of various clothing and skin albedos during the 31 August 2007 field measurements, two additional CRT's were constructed and painted to have an albedo that represented light clothing $\left(\alpha_{h}=0.57\right)$ and dark clothing $\left(\alpha_{h}=0.21\right)$. The CRT was designed to minimize the effects of terrestrial radiation on the sensor by inserting it $2 \mathrm{~mm}$ into a piece of wood dowel, $60 \mathrm{~mm}$ in length and $25 \mathrm{~mm}$ in diameter. A metal rod $9 \mathrm{~mm}$ in diameter was then inserted $2 \mathrm{~mm}$ into the opposite end of the dowel for mounting in a clamp, and the CRTs were secured at $90^{\circ}$ to the ground surface.

Wind velocity was measured using a cup anemometer (Metone 014A; Metone, USA). For the June 2007 field tests, air temperature was collected as the hourly average from a Stevenson screen located at the on-site Environment Canada weather station, approximately $50 \mathrm{~m}$ from the test site. For the August 2007 field tests, 
Fig. 1 A CRT constructed from a piece of copper pipe painted to have radiative properties similar to a clothed CRT, the pipe was filled with thermocouple was inserted to the mid-point of the pipe. The CRT was mounted using a metal rod, which was inserted into a piece of 1-in $(2.54-\mathrm{cm})$ wood dowel human. To construct the a conductive epoxy and a

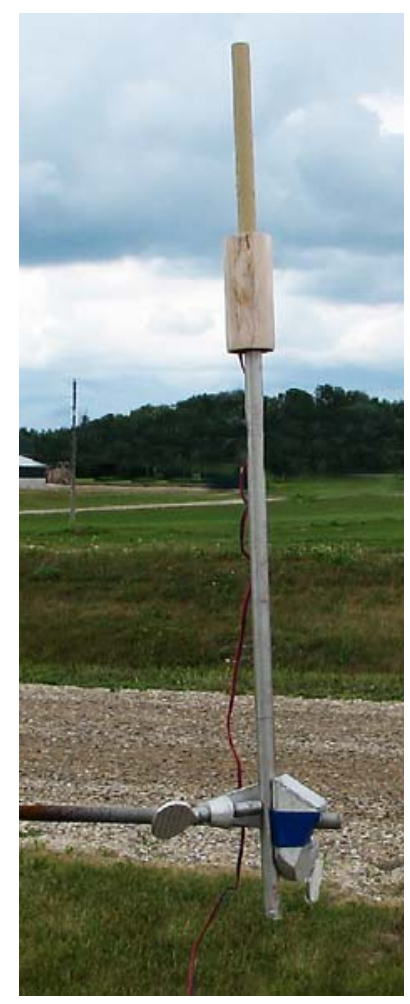

air temperature was measured using a thermocouple which was placed in a naturally ventilated radiation shield (Young, USA). Relative humidity data was collected as the hourly average from a Stevenson screen located at the weather station.

All four radiation flux components $\left(K_{t}, K_{r}, L_{a}\right.$, and $L_{g}$ ) were measured separately using a CNR1 net radiometer (Model CNR1; Kipp \& Konen) that was leveled prior to each field test.

Data were collected at 10 -s intervals using a datalogger (model 21X; Campbell Scientific Instruments, Logan, UT) and calculated as an average over a 5-min sampling period. In order to apply the hourly data collected at the research station, the data collected in June 2007 were assessed based on 60-min averages.

All instruments were secured at 1.5-1.7 m above the ground. It was ensured that no shadows were cast on either the CRT's or the CNR1 net radiometer during the field testing.

\section{Evaluation of the $R$ models}

Statistical evaluation of the difference between the methods used to estimate $R$ was conducted based on the Mean Bias Error, calculated as:

$M B E=\frac{\sum R_{a}-R_{b}}{n}$ where $R_{a}$ and $R_{b}$ represent the respective methods for estimating the radiation absorbed by a human and $n$ is the total number of measurements evaluated. The Mean Absolute Deviation was calculated as:

$M A D=\frac{\sum\left|R_{a}-R_{b}\right|}{n}$

The Root Mean Square Error was calculated as:

$R M S E=\sqrt{\frac{\sum\left(R_{a}-R_{b}\right)^{2}}{n}}$

\section{Results and discussion}

Estimating atmospheric transmissivity under clear sky conditions

Table 1 presents a summary of the meteorological conditions during the field tests conducted under clear skies. Atmospheric transmissivity $(\tau)$ varies both spatially and temporally depending upon the "turbidity' of the atmosphere. A $\tau$ value of less than 0.4 indicates overcast skies and a $\tau$ value of greater than 0.75 indicates very clear skies (Baigorria et al. 2004; Campbell and Norman 1998). The $\tau$ value for each day was determined by the RMSE between the $K_{t}$ estimated by equation (6), and the $K_{t}$ measured by the CNR1 net radiometer, calculated at $\tau$ values ranging from 0.40 to 0.80 (e.g. Fig. 2). The lowest $\tau$ value $(0.58)$ was calculated on 13 June 2007 and highest $\tau$ value (0.71) was calculated on 31 August 2007. Although all field measurements were conducted under clear skies, smog episodes are common in Southern Ontario during periods of warm, humid weather in the summer (Rainham and Smoyer-Tomic 2003). Smog advisories were issued by the Ontario Ministry of the Environment from 13 to 15 June 2007 which may account for the lower atmospheric transmissivity values on these

Table 1 Summary of the meteorological conditions recorded 11-14 June and 31 August, 2007 at the Elora Meteorological Research Station, ON, under clear sky conditions

\begin{tabular}{lllll}
\hline Date & $\overline{T a}\left({ }^{\circ} \mathrm{C}\right)^{\mathrm{a}}$ & $\overline{R H}(\%)$ & $\bar{V}\left(\mathrm{~m} \mathrm{~s}^{-1}\right)^{\mathrm{a}}$ & $\tau$ \\
\hline $2007 / 06 / 11$ & 24.0 & 38.7 & 2.8 & 0.61 \\
$2007 / 06 / 12$ & 28.2 & 33.5 & 3.8 & 0.60 \\
$2007 / 06 / 13$ & 28.8 & 38.2 & 3.4 & 0.58 \\
$2007 / 06 / 14$ & 23.2 & 48.6 & 3.2 & 0.62 \\
$2007 / 08 / 31$ & 22.5 & 42.8 & 3.9 & 0.71 \\
\hline
\end{tabular}

${ }^{\mathrm{a}}$ Air temperature and wind speed measured at $\mathrm{z}=1.5 \mathrm{~m}$ 


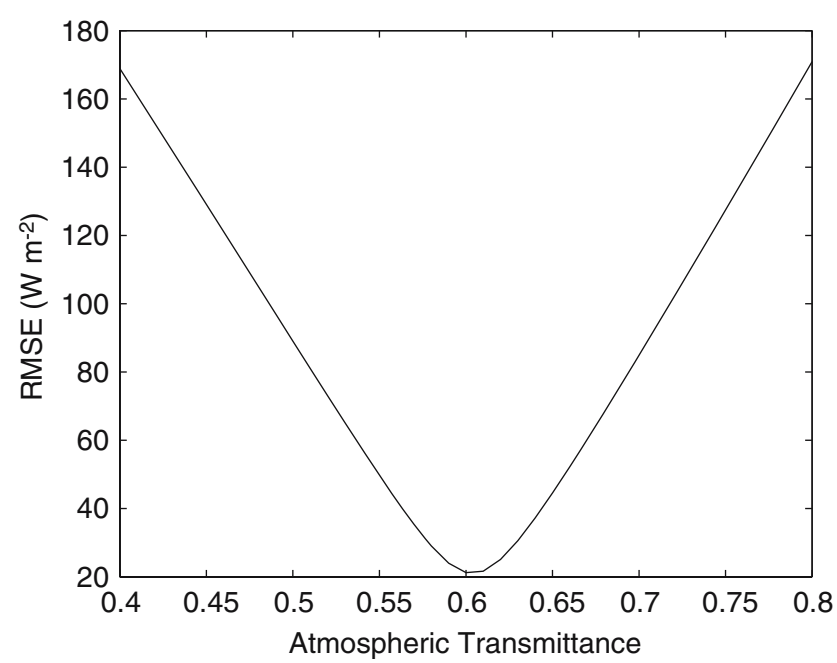

Fig. 2 RMSE between the estimated $K_{t}$ and the measured $K_{t}$ at various atmospheric transmissivity values for 12 June 2007 at the Elora Research Station, ON. The lowest RMSE was measured at an atmospheric transmissivity value of 0.60

days. The development of fair-weather cumulus clouds from ascending afternoon convection currents may also account for the lower atmospheric transmissivity values during the 11 to 14 June 2007 test periods.
Evaluating $R_{R T}, R_{E}$ and $R_{N R}$

Figure 3 provides the $R$ values based on the hourly data collected at the Elora Meteorological Research Station from 11 to 14 June 2007. The $R$ values ranged from approximately 540 to $620 \mathrm{~W} \mathrm{~m}^{-2}$ during the test periods. The hourly variation displays two distinct sinusoidaltype curves. The first over the course of the morning hours $(\sim 0800-1200 \mathrm{~h})$, and the second over the course of the afternoon hours $(\sim 1300-1800 \mathrm{~h})$. These curves clearly display the impact of direct beam solar radiation on a cylindrical body typical for the summer months in mid-latitude regions. During the morning hours, the $R$ values tended to increase with solar altitude to a maximum value at mid-morning and then decrease as the sun approached solar noon, when less direct beam radiation impacted the upright cylindrical shape. As short- and long-wave radiation inputs increased into the afternoon hours, the $R$ values peaked between $1500-1600 \mathrm{~h}$, and then began to decrease into the evening hours. Terjung and Louie (1971) describe these bimodal curves as occurring because the exposed area of a cylindrical body declines more rapidly with a decreasing zenith angle, than the increasing intensity of solar radiation received on a horizontal surface.
Fig. 3 Hourly variation (0800-1800 h) of the $R$ values based on the data collected on 11-14 June 2007 at the Elora Meteorological Research Station, ON, under clear sky conditions
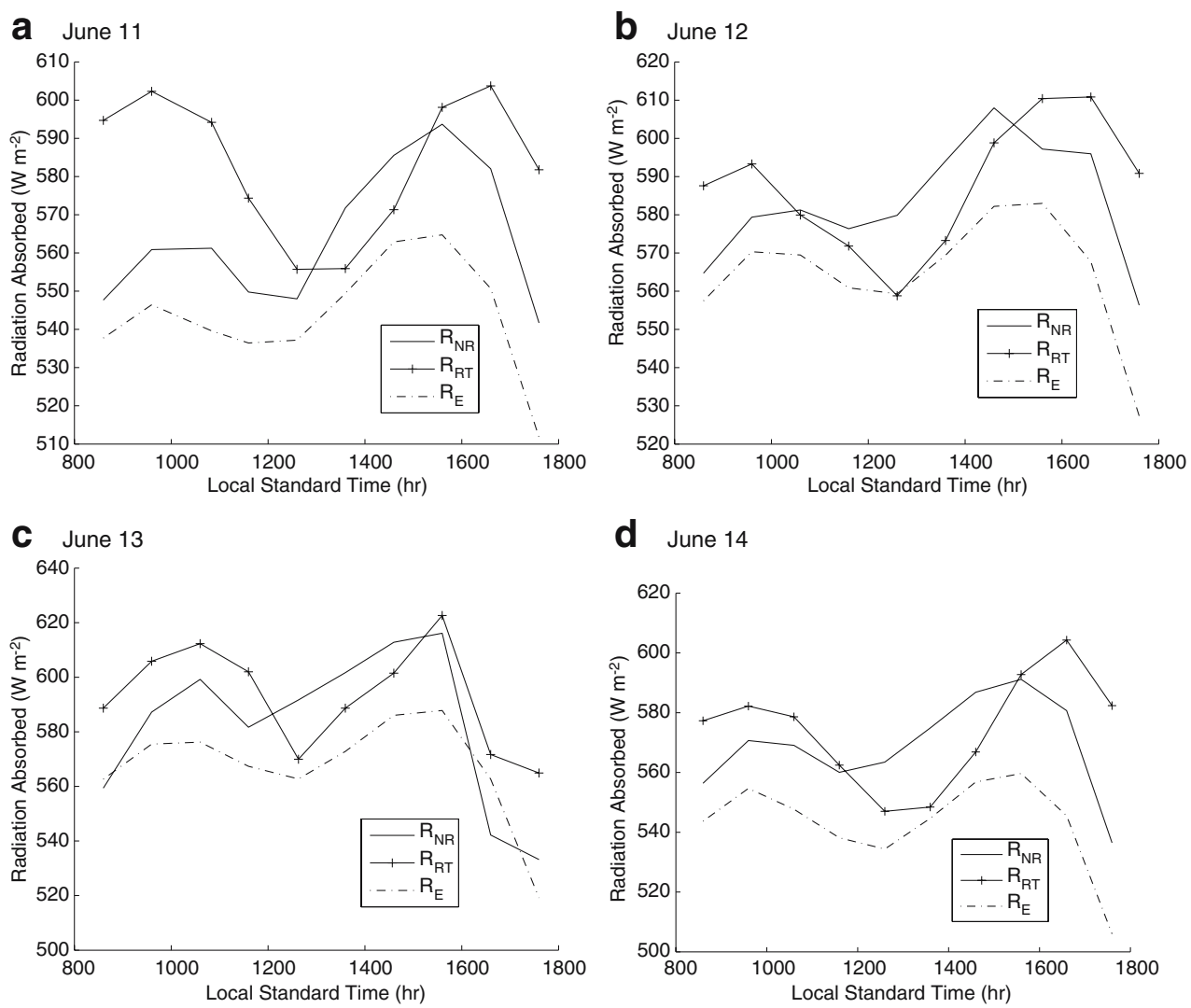

d June 14

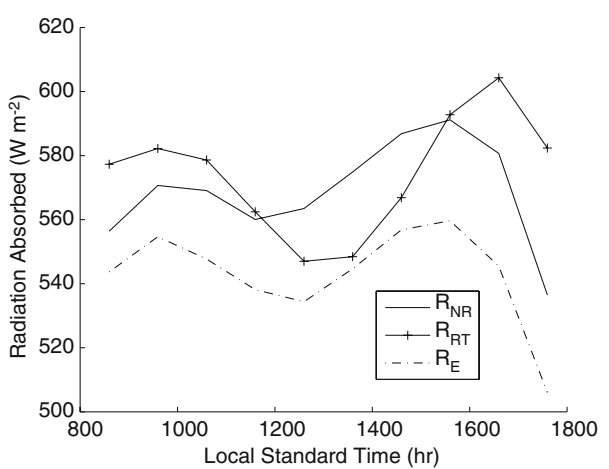


Table 2 Statistical evaluation of the differences in the $R$ values modeled using the estimation $\left(R_{E}\right)$, net radiometer $\left(R_{N R}\right)$, and the cylindrical radiation thermometer $\left(R_{R T}\right)$ methods for the data collected 11-14 June 2007 at the Elora Meteorological Research Station, ON

${ }^{a}$ Expressed as the percent of the mean of the variables analyzed

\begin{tabular}{lclll}
\hline & MBE $\left(\mathrm{W} \mathrm{m}^{-2}\right)$ & $\operatorname{MAD}\left(\mathrm{W} \mathrm{m}^{-2}\right)$ & $\operatorname{RMSE}\left(\mathrm{W} \mathrm{m}^{-2}\right)$ & $\mathrm{RMSE}(\%)^{\mathrm{a}}$ \\
\hline $\mathrm{R}_{R T}-\mathrm{R}_{N R}$ & & & & \\
$2007 / 06 / 11$ & 18.9 & 25.0 & 28.7 & 5.0 \\
$2007 / 06 / 12$ & 4.3 & 15.6 & 18.1 & 3.1 \\
$2007 / 06 / 13$ & 10.3 & 19.5 & 21.2 & 3.6 \\
$2007 / 06 / 14$ & 5.3 & 17.8 & 21.7 & 3.8 \\
$\mathrm{R}_{R T}-\mathrm{R}_{E}$ & & & & 7.9 \\
$2007 / 06 / 11$ & 39.5 & 39.5 & 44.8 & 5.1 \\
$2007 / 06 / 12$ & 22.8 & 22.9 & 29.3 & 4.0 \\
$2007 / 06 / 13$ & 25.5 & 25.5 & 23.2 & 5.5 \\
$2007 / 06 / 14$ & 31.0 & 31.1 & 30.6 & 4.0 \\
$\mathrm{R}_{N R}-\mathrm{R} E$ & & & & 3.5 \\
$2007 / 06 / 11$ & 20.9 & 20.5 & 21.9 & 3.8 \\
$2007 / 06 / 12$ & 18.9 & 18.6 & 20.0 & 4.8 \\
$2007 / 06 / 13$ & 11.5 & 20.0 & 21.7 & 26.8 \\
$2007 / 06 / 14$ & 25.6 & 25.8 & &
\end{tabular}

Thus, the daily noontime direct beam solar load on the cylinder is lower for high-sun periods. In the midlatitude winter months, when the sun maintains a low solar altitude, the diurnal $R$ curve would be expected to be bell-shaped, with a maximum value attained at the time of solar noon.

There was good agreement between the $R_{N R}$ and $R_{E}$ methods over the entire sampling periods (RMSE = 20-27 $\mathrm{W} \mathrm{m}^{-2}$ ) (Table 2). The estimation method showed a bias toward underestimating both the on-site net radiometer and cylindrical radiation thermometer methods. With the exception of 13 June, there is a distinct phase shift in the results generated by the $R_{R T}$ model. This phase shift may reflect the delayed response of the temperature of the cylinder to the impacts of radiation, as the CRT measurements are modeled based on the cylinder's energy budget - a steady state output. It may also be a consequence of calculating $R$ as an hourly average. Due to the high spatial and temporal variability of $R$ and its importance to the human energy balance equation, it may be more effective to calculate $R$ based on shorter time periods (i.e. $\leq 15 \mathrm{~min}$ ).

The $R_{R T}$ tended to overestimate $R$ during the morning hours, especially on 11 June. As the instruments remained exposed at night, it is possible that dew as a consequence of radiational cooling on clear calm nights, interfered with the sensor measurements during the morning hours. The CRT is designed to function in dry conditions and equation (16) does not consider the evaporative heat losses of the cylinder. When moist, the radiation absorbed by the cylinder becomes equal to the terrestrial radiation emitted plus the convective heat losses plus the evaporative heat losses. Thus, when moist, the CRT will overestimate the radiation absorbed.
The RMSE between the methods was lowest (18$30 \mathrm{~W} \mathrm{~m}^{-2}$ ) from 12 to 14 June. For all sampling days, the best agreement between the $R_{R T}$ and the $R_{N R}$ and $R_{E}$ models generally occurred between the hours of 1100 to $1600 \mathrm{~h}$ (zenith angle $\sim 20-50^{\circ}$ ), when both the short- and long-wave radiation inputs were greatest. During all sampling periods, the range of error between the methods used to estimate the radiation absorbed by a cylindrical body under clear sky conditions was tolerable (3.1-7.9\%).

Figure 4 displays the $R$ values obtained using the net radiometer and the cylindrical radiation thermometer under overcast conditions at the Elora Research Station, ON. During the entire test period the sun was entirely obscured by low-lying stratiform clouds. The

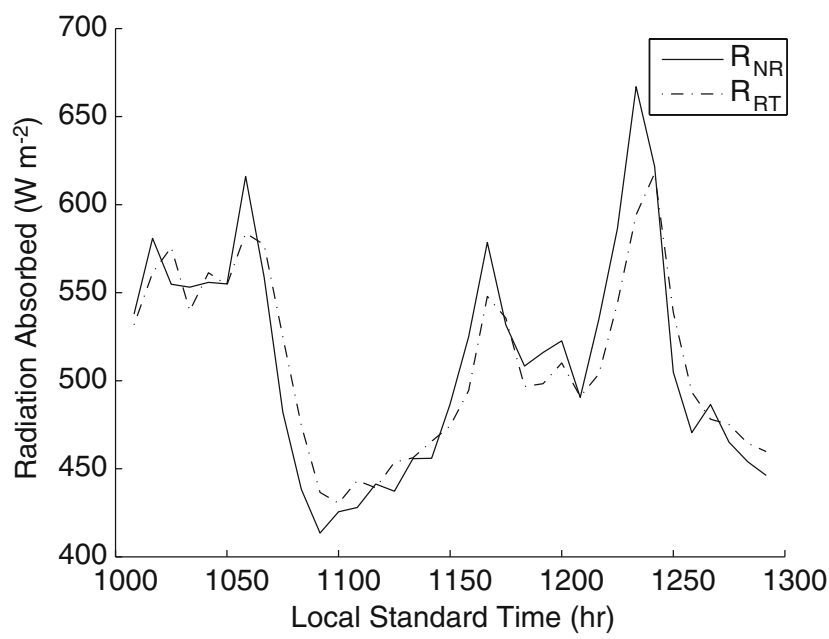

Fig. 4 Hourly variation (1000-1300 h) of the $R$ values based on the data collected on 22 August 2007 at the Elora Meteorological Research Station, ON, under overcast conditions 
average air temperature, wind speed $(\mathrm{z}=1.5 \mathrm{~m})$ and relative humidity were $20.0^{\circ} \mathrm{C}, 2.4 \mathrm{~ms}^{-1}$ and $100 \%$, respectively. The $R$ values ranged from approximately 415 to $670 \mathrm{~W} \mathrm{~m}^{-2}$. There was good agreement (RMSE = $22 \mathrm{~W} \mathrm{~m}^{-2}$ or $4.4 \%$ ) between both the net radiometer and CRT methods.

As the challenges of accurate design and development for short- and long-wave radiation measurements make them inherently difficult meteorological variables to measure, reasonable estimates are considered generally acceptable within $10 \%$ of the measured value (Gul et al. 1998; Podesta et al. 2004; Swift and Knoerr 1973). The results obtained in this study are very similar to those produced by Krys and Brown (1990) who concluded that a CRT and weather station estimation model measured $R$ within a $10 \%$ range of error of that calculated using on-site measurements. The benefits of the present study are that it:

- presented a simple method of estimating $R$ in the absence of on-site measurements;

- provided a convenient means of modeling $R$ based on planar radiation measurements;

- presented a comprehensive assessment of the daily variation (0800-1800h) of $R$;

- evaluated the performance of a net radiometer and CRT under overcast skies.

\section{Albedo test}

Figure 5 compares the impact of applying the various $\alpha_{h}$ values on the $R$ output for the three calculation methods. All methods of calculating the radiation absorbed by a human were sensitive to the changes in $\alpha_{h}$. Over the sampling period, $R$ ranged from approximately 600 to $710 \mathrm{~W} \mathrm{~m}^{-2}$ for the darkest albedo $\left(\alpha_{h}=0.21\right)$, 560 to $600 \mathrm{~W} \mathrm{~m}^{-2}$ for the medium albedo $\left(\alpha_{h}=0.37\right)$, and 475 to $530 \mathrm{~W} \mathrm{~m}^{-2}$ for the lightest albedo $\left(\alpha_{h}=\right.$ $0.57)$. The mean change in $R$ between the darkest and lightest albedo ranged from 115 to $157 \mathrm{~W} \mathrm{~m}^{-2}$ over the sampling period.

These results are similar to the results produced by Blazejczyk et al. (1998) who measured differences in the solar radiation absorbed by black $(\alpha=0.03)$ and white $(\alpha=0.95)$ fabric of approximately $100 \mathrm{~W} \mathrm{~m}^{-2}$ and concluded that color of fabric strongly affects the absorption of direct and diffuse beam solar radiation. The results in the present study suggest that it is important to accurately represent the clothing and skin albedo of subjects when estimating $R$. Although the heat absorption due to the solar heat load is greater for dark-colored clothing than for light-colored clothing, whether this would translate into a greater heat strain for the subject depends on other factors in the human heat balance equation such as the insulation value of
Fig. 5 Hourly variation (1100-1600 h) in the $R$ values calculated at light $\left(\alpha_{h}=0.57\right)$, medium $\left(\alpha_{h}=0.37\right)$, and dark $\left(\alpha_{h}=0.21\right)$ clothing and skin albedos under clear sky conditions on 31 August 2007 at the Elora Research Station, ON
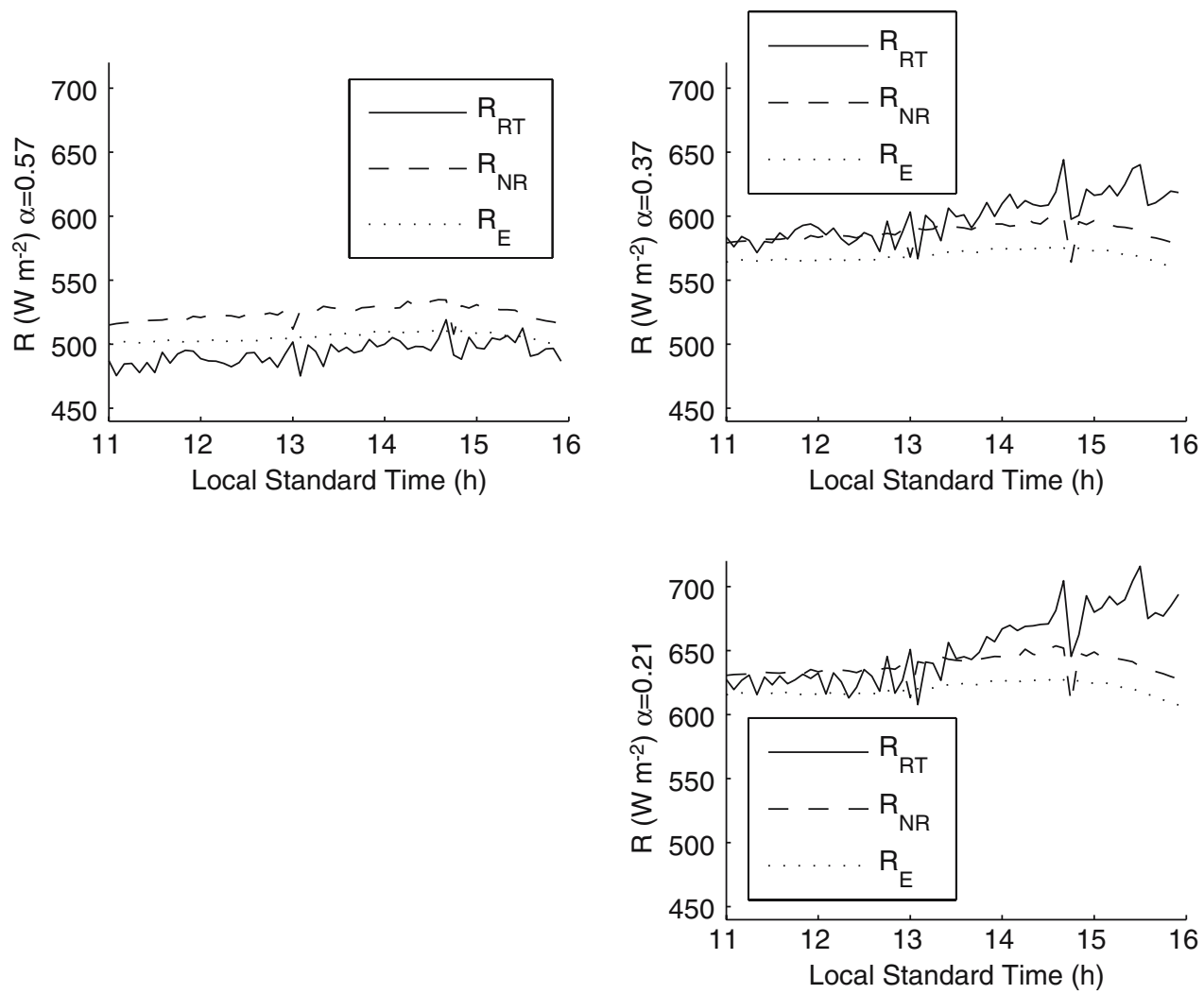
the clothing, the boundary air resistance, and the ambient air temperature, relative humidity and wind speed (Nielsen 1990).

\section{$R$ and outdoor thermal comfort}

Thermal comfort models are commonly applied as a predictive tool to assess human responses to thermal environments. There is a wide range in sophistication of thermal comfort models, but they all evaluate the heat and moisture exchange with the environment, determine a balance between heat generated within the body and dissipated to the environment, and relate this physiological response to perceptions of thermal sensation (Jones 2002). The human heat balance equation is composed of the following inputs: metabolism, and short- and long-wave radiation absorbed. In order for thermal comfort to be achieved, the positive inputs of metabolism and the short- and long-wave radiation absorbed must be balanced by the following outputs: convection, evaporation, and the terrestrial radiation emitted by the body.

To apply the vertical cylinder $R$ models proposed in this study, the effective radiation area factor $\left(A_{e f f}\right)$, which accounts for irregularities of the human body and inter-radiative exchange between body parts ( 0.78 for standing, 0.70 for seated, and 0.66 for crouched position (Kerslake 1972)) must be integrated into equations (15) and (16) as follows:

$$
\begin{aligned}
& R=A_{e f f} \frac{K_{b(a b s)}+K_{d(a b s)}+L_{a(a b s)}+L_{g(a b s)}}{A_{c y l}} \\
& R_{R T}=A_{e f f}\left(\varepsilon \sigma\left(T_{r t}+273.15\right)^{4}+\rho C_{p} \frac{\left(T_{r t}-T_{a}\right)}{r_{m}}\right)
\end{aligned}
$$

The relative importance of obtaining an accurate estimate of $R$ can be assessed in Table 3. Under clear sky conditions, $R$ was approximately four times the amount of the metabolic input of a standing person in all circumstances. Under the average conditions measured on 31 August 2007 a subject wearing dark clothing would have been warm, while a subject wearing medium toned or light clothing would have been comfortable (the subject wearing light clothing would be on the border line of feeling cool). These results clearly demonstrate that in an outdoor environment, under clear sky conditions, the total short- and long-wave radiation input will be much in excess of the metabolic input of a human sitting, standing or performing mild to moderate physical activity (see Ainsworth et al. 2000 for a complete

Table 3 Energy balance of a subject standing in an outdoor environment at various clothing and skin albedos $\left(\alpha_{h}\right)$ given the average

\begin{tabular}{|c|c|c|c|}
\hline & August 31st & & \\
\hline \multicolumn{4}{|l|}{ Input variables } \\
\hline $\mathrm{T}_{a}\left({ }^{o} \mathrm{C}\right)$ & 22.5 & & \\
\hline $\mathrm{RH}(\%)$ & 42.8 & & \\
\hline$r_{c o}\left(\mathrm{~s} \mathrm{~m}^{-1}\right)^{\mathrm{b}}$ & 90 & & \\
\hline$P\left(\mathrm{ft}^{3} \mathrm{ft}^{-2} \min ^{-1}\right)^{\mathrm{c}}$ & 200 & & \\
\hline$V\left(\mathrm{~m} \mathrm{~s}^{-1}\right)$ & 3.9 & & \\
\hline Metabolic activity ${ }^{\mathrm{d}}\left(\mathrm{W} \mathrm{m}^{-2}\right)$ & 116 & & \\
\hline \multicolumn{4}{|c|}{ Energy budget components $\left(\mathrm{W} \mathrm{m}^{-2}\right)$} \\
\hline & $\alpha_{h}=0.57$ & $\alpha_{h}=0.37$ & $\alpha_{h}=0.21$ \\
\hline$R^{\mathrm{e}}$ & 395 & 455 & 495 \\
\hline Metabolism & 105 & 105 & 105 \\
\hline Convection & -156 & -156 & -156 \\
\hline Evaporation & -29 & -29 & -29 \\
\hline Long-wave radiation emitted & -356 & -356 & -356 \\
\hline Overall budget & -41 & 19 & 58 \\
\hline Comfort level $^{\mathrm{f}}$ & Comfortable & Comfortable & Warm \\
\hline
\end{tabular}
conditions measured during the field tests on 31 August 2007 at the Elora Research Station, ON ${ }^{\text {a }}$

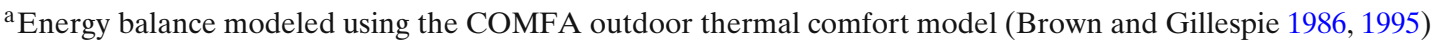

${ }^{\mathrm{b}}$ Resistance of clothing (ISODIS9920 2004), 1 clo $=187 \mathrm{~s} \mathrm{~m}^{-1}$

${ }^{\mathrm{c}}$ Permeability of clothing (ISODIS9920 2004)

d (Ainsworth et al. 2000)

e Average of $R_{N R}, R_{R T}$, and $R_{E}$ reduced by $A_{\text {eff }}=0.78$

${ }^{\mathrm{f}}$ Comfort is achieved between -50 and $+50 \mathrm{~W} \mathrm{~m}^{-2}$ (Brown and Gillespie 1986, 1995) 
description of metabolic activity rates). It also confirmed that it is very important to consider clothing and skin albedo $\left(\alpha_{h}\right)$ in outdoor thermal comfort research. All methods for calculating $R$ in this study are designed to provide reliable estimates of $\alpha_{h}$.

\section{Conclusion}

Radiation is one of the most important variables to consider in outdoor thermal comfort research, especially when subjects are exposed to substantial amounts of solar radiation. The radiation absorbed by a human in an outdoor environment is often the largest contributor to the human energy balance equation. As short- and long-wave radiation received in an outdoor environment can vary substantially over space and time, it is increasingly important to make accurate estimates of the impact of radiation on a human. Due to the complexities of the atmospheric and terrestrial radiative environment, the total long- and short-wave radiation absorbed by the human body is difficult to quantify. The three methods assessed in this study provided estimates of $R$ by a vertical cylinder under clear sky conditions to within 3-8\% error of each other. This study also confirmed that accurately representing the combined skin and clothing albedo of subjects is extremely important when estimating $R$, where differences between light and dark albedos can range in excess of $100 \mathrm{~W} \mathrm{~m}^{-2}$.

There are advantages and disadvantages associated with all of the above methods. The estimation model requires no instrumentation and is therefore easily applied to any location. However, under fluctuating cloud-cover conditions, reliable estimations of the incoming short- and long-wave fluxes become increasingly difficult to obtain. For application in outdoor thermal comfort studies, on-site measurements are preferable. Net radiometers provide the most accurate and reliable measurements for incoming and outgoing radiation fluxes, but are relatively expensive and cumbersome to operate. Although it has been recommended that the radiation environment of a human be established in three-dimensional form, where a combination of pyranometer and pyrgeometer measurements are required in six directions to accurately represent the complete short- and long-wave fluxes incident on the body (Matzarakis et al. 2007; Parsons 2003), the $R_{E}$ and $R_{N R}$ methods proposed in this study were conveniently based on just the horizontal measurements.

The direct beam solar radiation incident on a cylinder has a large impact on $R$. It is very important to separate the total incoming short-wave radiation measurement into the direct and diffuse beam components, due to their varying geometries. The presence of clouds can cause wide fluctuations in the total incoming direct and diffuse beam short-wave radiation fluxes (see equations (9) and (10)). Although empirical models are available to provide estimates of the ratio of incoming direct to diffuse beam radiation under cloudy conditions, it becomes more erroneous to model the total solar radiation absorbed under overcast conditions, which is a disadvantage of the $R_{E}$ method.

The CRT represents a convenient, inexpensive method for providing on-site $R$ measurements under a variety of cloud-cover conditions. As the cylinder is especially sensitive to solar heat gain in association with the amount of short-wave radiation absorbed, care must be taken in selecting the correct $\alpha_{h}$ value to apply to the cylinder. As the CRT measurements are modeled based on the cylinder's energy budget, which is a steady-state output, there may be a delayed response of the temperature of the cylinder to the impacts of radiation.

The interactions between short- and long-wave radiation fluxes in the sky and ground hemispheres and the human body are complex and make it difficult to precisely estimate the total radiation absorbed by a human in an outdoor environment. This study outlined and assessed three methods for estimating $R$ based on theoretical principles of meteorological biophysics that can be conveniently applied to provide reliable estimates of the radiation absorbed by a human in an outdoor environment.

\section{References}

Ainsworth B, Haskell W, Whitt M, Irwin M, Swartz A, Strath S, O'Brien W, Bassett D Jr, Schmitz K, Emplaincourt P, Jacobs D Jr, Leon A (2000) Compendium of physical activities: an update of activity codes and MET intensities. Med Sci Sports Exerc 32:S498-S516

Ali-Toudert F, Djenane M, Bensalem R, Mayer H (2005) Outdoor thermal comfort in the old desert city of Beni-Isguen, Algeria. Clim Res 28:243-256

Ali-Toudert F, Mayer H (2006) Numerical study on the effects of aspect ratio and orientation of an urban street canyon on outdoor thermal comfort in hot and dry climate. Build Environ 41:94-108

Baigorria G, Billegas E, Trebejo I, Carlos J, Quiroz R (2004) Atmospheric transmissivity: distribution and empirical estimation around the central Andes. Int $\mathrm{J}$ Climatol 24:1121-1136

Blazejczyk K, Holmer I, Nilsson H (1998) Absorption of solar radiation by an ellipsoid sensor simulated the human body. Appl Hum Sci 17(6):267-273

Blazejczyk K, Nilsson H, Holmer I (1993) Solar heat load on man: review of different methods of estimation. Int J Biometeorol $37: 125-132$ 
Brock F, Richardson S (2001) Meteorological measurement systems. Oxford University Press, Oxford

Brown R, Gillespie T (1986) Estimating outdoor thermal comfort using a cylindrical radiation thermometer and an energy budget model. Int J Biometeorol 30(1):43-52

Brown R, Gillespie T (1995) Microclimatic landscape design. John Wiley \& Sons, Inc

Campbell G (1977) An introduction to environmental biophysics. Springer, New York Berlin Heidelberg

Campbell G, Norman J (1998) An introduction to environmental biophysics, 2nd edn. Springer, New York Berlin Heidelberg

Driscoll D (1985) Human health. In: Houghton D (ed) Handbook of applied meteorology. Wiley, New York, pp 778-814

Fanger P (1972) Thermal comfort. McGraw-Hill, New York

Gul S, Muneer T, Kambezidis H (1998) Models for obtaining solar radiation from other meteorological data. Sol Energy 64(1-3):99-108

Hodder S, Parsons K (2007) The effects of solar radiation on thermal comfort. Int J Biometeorol 51:233-250

ISODIS9920 (2004) Ergonomics of the thermal environment estimation of the thermal insulation and the water resistance of a clothing ensemble. Technical Report ISODIS9920, International Standards Organization

Jendritzky G, Nubler W (1981) A model analysing the urban thermal environment in physiologically significant terms. Arch Meteorol Geophys Bioclimatol 29:313-326

Jones B (2002) Capabilities and limitations of thermal models for use in thermal comfort standards. Energy Build 34:653-659

Kerslake D (1972) The stress of hot environments. Cambridge University Press, London

Kreith F, Black W (1980) Basic heat transfer. Harper \& Row, New York

Krys S, Brown R (1990) Radiation absorbed by a vertical cylinder in complex outdoor environments under clear sky conditions. Int J Biometeorol 34:69-75

La Gennusa M, Nucara A, Rizzo G, Scaccianoce G (2005) The calculation of the mean radiant temperature of a subject exposed to the solar radiation - a generalised algorithm. Build Environ 40:365-373

Matzarakis A, Rutz F, Mayer H (2007) Modelling radiation fluxes in simple and complex environments - application of the RayMan model. Int J Biometeorol 51:323-334

Monteith J, Unsworth M (1990) Principles of environmental physics, 2nd edn. Butterworth-Heinemann, Boston, Mass

Nielsen B (1990) Solar heat load: heat balance during exercise in clothed subjects. Eur J Appl Physiol 60:452-456

Nikolopoulou M, Baker N, Steemers K (2001) Thermal comfort in outdoor urban spaces: understanding the human parameter. Sol Energy 70(3):227-235

Nikolopoulou M, Lykoudis S (2006) Thermal comfort in outdoor urban spaces: analysis across different European countries. Build Environ 41:1455-1470

Oke T (1987) Boundary layer climates, 2nd edn. Routledge Taylor \& Francis, New York

Parsons K (2003) Human thermal environments, 2nd edn. Taylor \& Francis, New York

Podesta G, Nunez L, Villanueva C, Skansi M (2004) Estimating daily solar radiation in the Argentine Pampas. Agric For Meteorol 123:41-53

Rainham D, Smoyer-Tomic K (2003) The role of air pollution in the relationship between a heat stress index and human mortality in Toronto. Environ Res 93:9-19

Schiller G (2001) Biometeorology and recreation in east Mediterranean forests. Landsc Urban Plan 57:1-12

Swift L, Knoerr K (1973) Estimating solar radiation on mountain slopes. Agric Meteorol 12:329-336

Terjung W, Louie SS-F (1971) Potential solar radiation climates of man. Ann Assoc Am Geogr 61(3):481-500

Thorsson S, Lindberg F, Eliasson I, Holmer B (2007) Different methods for estimating the mean radiant temperature in an outdoor urban setting. Int J Climatol (27):19831993

Thorsson S, Lindqvist M, Lindqvist S (2004) Thermal bioclimatic conditions and patterns of behaviour in an urban park in Goteborg, Sweden. Int J Biometeor 48:149-156 